\title{
Meta-analysis
}

\section{Dietary glycaemic index and glycaemic load in relation to the risk of type 2 diabetes: a meta-analysis of prospective cohort studies}

\author{
Jia-Yi Dong ${ }^{1}$, Lijun Zhang ${ }^{2}$, Yong-Hong Zhang ${ }^{2}$ and Li-Qiang Qin ${ }^{1_{*}}$ \\ ${ }^{1}$ Department of Nutrition and Food Hygiene, School of Public Health, Soochow University, Suzhou, Republic of China \\ ${ }^{2}$ Department of Epidemiology, School of Public Health, Soochow University, Suzhou, Republic of China
}

(Received 11 April 2011 - Revised 19 July 2011 - Accepted 4 September 2011 - First published online 29 September 2011)

\section{Abstract}

Epidemiological studies of dietary glycaemic index (GI) and glycaemic load (GL) in relation to diabetes risk have yielded inconsistent results. We aimed to examine the associations between dietary GI and GL and the risk of type 2 diabetes by conducting a meta-analysis of prospective cohort studies. Relevant studies were identified by a PubMed database search up to February 2011. Reference lists from retrieved articles were also reviewed. We included prospective cohort studies that reported risk estimates with $95 \%$ CI for the associations between dietary GI and GL and the risk of type 2 diabetes. Either a fixed- or random-effects model was used to compute the summary relative risk (RR). We identified thirteen prospective cohort studies of dietary GI or GL related to diabetes risk. The summary RR of type 2 diabetes for the highest category of the GI compared with the lowest was $1.16(95 \%$ CI $1 \cdot 06,1 \cdot 26 ; n 12)$, with moderate evidence of heterogeneity $(P=0 \cdot 02$, $\left.I^{2}=50 \cdot 8 \%\right)$. For the GL, the summary RR was 1.20 (95\% CI $\left.1 \cdot 11,1 \cdot 30 ; n 12\right)$, with little evidence of heterogeneity $\left(P=0 \cdot 10, I^{2}=34 \cdot 8 \%\right)$. No evidence of publication bias was observed. In addition, the associations persisted and remained statistically significant in the sensitivity analyses. In conclusion, the present meta-analysis provides further evidence in support of significantly positive associations between dietary GI and GL and the risk of type 2 diabetes. Reducing the intake of high-GI foods may bring benefits in diabetes prevention.

Key words: Diabetes mellitus: Glycaemic index: Glycaemic load: Meta-analysis

Type 2 diabetes has been a growing public health problem worldwide $^{(1)}$. A large body of evidence has demonstrated that the presence of diabetes doubles the risk of a wide range of vascular diseases $^{(2)}$. In addition, diabetes is moderately associated with death from cancers of the liver, pancreas, ovary, colorectum, lung, bladder and breast ${ }^{(3)}$. Preventive strategies are urgently needed to reduce the huge burden of diabetes.

Diet is widely believed to play an important role in the development of type 2 diabetes $^{(4,5)}$. Dietary glycaemic index (GI) and glycaemic load (GL) have received considerable attention for their potential contribution to the diabetes epidemic. The GI, introduced by Jenkins et $a l^{(6)}$, ranks the carbohydrate content of individual foods according to their postprandial glycaemic effects. Consumption of high-GI diets is associated with high blood glucose and insulin concentrations, thereby eventually resulting in glucose intolerance and high diabetes risk $^{(7,8)}$. The GL, which is the product of the GI of a food item and the available carbohydrate content, quantifies the overall glycaemic effect and insulin demand ${ }^{(9,10)}$.
Prospective cohort studies assessing the effects of dietary GI and GL on the risk of type 2 diabetes have yielded inconsistent results $^{(9-21)}$. A previous meta-analysis of seven studies found that diets with a high GI or GL significantly increased the risk of type 2 diabetes $^{(22)}$. During the past few years, the number of original studies linking dietary GI and GL to diabetes has doubled. However, not all confirmed the previous findings, and the controversy on this topic continues ${ }^{(17,19)}$. With accumulating evidence, we therefore aimed to examine the associations between dietary GI and GL and the risk of type 2 diabetes by conducting an updated meta-analysis of prospective cohort studies.

\section{Materials and methods}

\section{Literature search}

We conducted a PubMed database search up to February 2011 to identify published studies of dietary GI and GL and the

Abbreviations: GI, glycaemic index; GL, glycaemic load; RR, relative risk.

*Corresponding author: Dr L.-Q. Qin, fax +86 512 65880050, email dongjy@mail3.sysu.edu.cn 
risk of type 2 diabetes, using the search terms 'glycemic index' or 'glycemic load' in combination with 'diabetes'. No restrictions were imposed. In addition, we reviewed the reference lists of retrieved articles. Efforts were made to obtain additional data by contacting original authors.

\section{Study selection}

Studies were eligible for the present meta-analysis if they met the following criteria: a prospective cohort design, which is less prone to bias than a retrospective one; the exposure of interest was dietary GI or GL; the outcome of interest was incidence of type 2 diabetes; risk estimates and associated 95\% CI (or data to calculate them) were reported.

\section{Data extraction}

The following information was independently extracted by two authors: the first author's last name, publication year; study population, location, length of follow-up; number of cases and participants; assessment of exposure and outcome; most fully adjusted risk estimates with corresponding 95\% CI from the multivariable model for each category of exposure or for exposure as a continuous variable; statistical adjustment for the potential confounding factors.

\section{Statistical analysis}

The relative risk (RR) was used as the common measure of association across studies. For four studies ${ }^{(12,13,15,21)}$ that analysed exposure as a continuous variable, RR for categories of exposure were obtained from original authors or estimated based on the exposure range (i.e. the highest and lowest categories of exposure) reported in the primary studies. A sensitivity analysis was performed by excluding these four studies to test the robustness of the results.

We calculated the $Q$ and $I^{2}$ statistics to examine statistical heterogeneity across studies. $I^{2}$ is the proportion of total variation explained by between-study variation ${ }^{(23)}$. Either a fixedor, in the presence of heterogeneity, random-effects model ${ }^{(24)}$ was used to compute the summary risk estimates. In the fixed-effects model, the weight of each study is equal to the inverse variance of the natural logarithm of the RR, whereas in the random-effects model, an extra term is added to the variance according to the method proposed by DerSimonian \& Laird $^{(24)}$. In addition, we examined the influence of a single study on the combined risk estimates by omitting one study and analysing the remainders in each turn. Potential publication bias was assessed by visual inspection of Begg's funnel plots and by the Begg rank correlation and Egger linear regression tests ${ }^{(25,26)}$. All analyses were performed with the use of STATA version 11.0 (StataCorp, College Station, TX, USA). All statistical tests were two-sided and $P<0.05$ was considered statistically significant, except where otherwise specified.

\section{Results}

\section{Study characteristics}

We identified sixteen potentially relevant prospective cohort studies of GI and GL and type 2 diabetes. Of these sixteen studies, three were excluded because the outcome was gestational diabetes mellitus ${ }^{(27)}$ or because of overlapping publications from the same study population ${ }^{(28,29)}$, thus leaving thirteen studies ${ }^{(9-21)}$ (twelve for GI and twelve for GL) for the final analysis. Characteristics of the selected studies are presented in Table 1. The association between GI and GL and diabetes risk was the primary outcome in all primary studies. The thirteen prospective cohort studies were published between 1997 and 2010. Among them, eight studies were conducted in the USA, two in Europe, two in Australia and one in China. The number of cases diagnosed in the original studies ranged from 138 to 8587 , and the size of the cohort ranged from 1833 to 91249 . Of these thirteen studies, seven enrolled both sexes, one included men only and five included women only. The median length of follow-up ranged from 4 to 14 years. All studies used FFQ in dietary assessment. Diabetes ascertainment was based on self-report of physician diagnosis in most studies, but the majority of cases were confirmed in validation studies. The major confounding factors of interest included age, BMI, physical activity, smoking, and intakes of total energy, alcohol and dietary fibre.

\section{Glycaemic index, glycaemic load and the risk of type 2 diabetes}

The multivariable-adjusted RR for each study and the combined RR comparing the highest with the lowest categories of the GI and GL are presented in Figs. 1 and 2. Among the included studies, six studies found a statistically significant association between GI and an increased risk of type 2 diabetes. The GL was significantly associated with an increased diabetes risk in four studies. The summary RR of type 2 diabetes for the highest category of GI compared with the lowest was $1 \cdot 16$ (95\% CI 1.06, 1.26; $n$ 12), with moderate evidence of heterogeneity $\left(P=0 \cdot 02, I^{2}=50 \cdot 8 \%\right)$. For the GL, the summary RR was $1 \cdot 20$ (95\% CI $1 \cdot 11,1 \cdot 30 ; n 12)$, with little evidence of heterogeneity $\left(P=0 \cdot 10, I^{2}=34 \cdot 8 \%\right)$. Visual inspection of Begg's funnel plots did not show important asymmetry for either exposure. The Begg rank correlation and Egger linear regression tests did not indicate evidence of publication bias (all $P>0 \cdot 30$ )

\section{Sensitivity analysis}

We also performed sensitivity analyses to test the robustness of the findings. Restricting analysis to studies that adjusted for total fibre or cereal fibre yielded a summary RR of 1.14 (95\% CI $1.03,1.26 ; n$ 10) for the GI and 1.16 (95\% CI 1.05 , $1 \cdot 29 ; n$ 9) for the GL. Restricting analysis to studies that were conducted in the USA yielded a summary RR of $1 \cdot 17$ (95\% CI $1.02,1.34 ; n$ 7) for the GI and 1.19 (95\% CI 1.08 , $1 \cdot 31 ; n$ ) for the GL. Restricting analysis to studies that analysed exposure as categorical variables yielded a summary 
Table 1. Characteristics of prospective cohort studies of dietary glycaemic index (GI) and glycaemic load (GL) and type 2 diabetes

\begin{tabular}{|c|c|c|c|c|c|c|}
\hline Study & Population (cases) & $\begin{array}{c}\text { Duration } \\
\text { (years) }\end{array}$ & $\begin{array}{l}\text { Dietary } \\
\text { assessment }\end{array}$ & Case ascertainment & Exposure & Adjustments \\
\hline Salmeron et al. $(1997)^{(9)}$ & $\begin{array}{l}42759 \text { men aged } 40-75 \text { years, } \\
\text { USA (523) }\end{array}$ & 6 & FFQ & Confirmed self-report & GI and GL & $\begin{array}{l}\text { Age, BMI, smoking, physical activity, family history } \\
\text { of diabetes, and intakes of alcohol, total energy } \\
\text { and cereal fibre }\end{array}$ \\
\hline Salmeron et al. $(1997)^{(10)}$ & $\begin{array}{l}65173 \text { women aged } 40-65 \text { years, } \\
\text { USA (951) }\end{array}$ & 6 & $\mathrm{FFQ}$ & Confirmed self-report & GI and GL & $\begin{array}{l}\text { Age, BMI, smoking, physical activity, family history } \\
\text { of diabetes, and intakes of alcohol, total energy } \\
\text { and cereal fibre }\end{array}$ \\
\hline Meyer et al. $(2000)^{(11)}$ & $\begin{array}{l}35988 \text { women aged } 55-69 \text { years, } \\
\text { USA (1141) }\end{array}$ & 6 & $\mathrm{FFQ}$ & Self-report & $\mathrm{Gl}$ and $\mathrm{GL}$ & $\begin{array}{l}\text { Age, BMI, WHR, education, smoking, physical } \\
\text { activity, and intakes of alcohol, total energy and } \\
\text { total fibre }\end{array}$ \\
\hline Stevens et al. $(2002)^{(12)}$ & $\begin{array}{l}12251 \text { adults aged } 45-64 \text { years, } \\
\text { USA (1447) }\end{array}$ & 9 & FFQ & Confirmed self-report & $\mathrm{Gl}$ and $\mathrm{GL}$ & $\begin{array}{l}\text { Age, BMI, sex, field centre, education, smoking, } \\
\text { physical activity and cereal fibre intake }\end{array}$ \\
\hline Hodge et al. $(2004)^{(13)}$ & $\begin{array}{l}34641 \text { adults aged } 40-69 \text { years, } \\
\text { Australia (365) }\end{array}$ & 4 & FFQ & Confirmed self-report & $\mathrm{Gl}$ and $\mathrm{GL}$ & $\begin{array}{l}\text { Age, BMI, WHR, weight change, education, sex, } \\
\text { country of birth, physical activity, family history } \\
\text { of diabetes, and intakes of alcohol and total } \\
\text { energy }\end{array}$ \\
\hline Schulze et al. $(2004)^{(14)}$ & $\begin{array}{l}91249 \text { women aged } 26-46 \text { years, } \\
\text { USA ( } 741)\end{array}$ & 8 & FFQ & Confirmed self-report & GI and GL & $\begin{array}{l}\text { Age, BMI, physical activity, history of high blood } \\
\text { pressure, oral contraceptive use, hormone } \\
\text { therapy, family history of diabetes, and intakes } \\
\text { of alcohol, fat, total energy, cereal fibre, caffeine } \\
\text { and } \mathrm{Mg}\end{array}$ \\
\hline Barclay et al. (2007) ${ }^{(15)}$ & $\begin{array}{l}1833 \text { adults aged }>49 \text { years, } \\
\text { Australia (138) }\end{array}$ & 10 & FFQ & $\begin{array}{l}\text { Glucose levels, use of diabetic } \\
\text { medication and self-report }\end{array}$ & GI & $\begin{array}{l}\text { Age, BMI, sex, family history of diabetes, smok- } \\
\text { ing, physical activity, TAG, HDL and vegetable } \\
\text { fibre intake }\end{array}$ \\
\hline Krishnan et al. $(2007)^{(16)}$ & $\begin{array}{l}59000 \text { women aged } 21-69 \text { years, } \\
\text { USA (1938) }\end{array}$ & 8 & $\mathrm{FFQ}$ & Confirmed self-report & $\mathrm{Gl}$ and $\mathrm{GL}$ & $\begin{array}{l}\text { Age, BMI, family history of diabetes, smoking, } \\
\text { physical activity, and intakes of cereal fibre, pro- } \\
\text { tein, total fat and total energy }\end{array}$ \\
\hline Mosdol et al. $(2007)^{(17)}$ & $\begin{array}{l}7321 \text { adults aged } 39-63 \text { years, } \\
\text { UK (329) }\end{array}$ & 13 & FFQ & $\begin{array}{l}\text { Glucose levels, use of diabetic } \\
\text { medication and self-report }\end{array}$ & $\mathrm{Gl}$ and $\mathrm{GL}$ & $\begin{array}{l}\text { Age, BMI, WHR, sex, employment, physical } \\
\text { activity, smoking, and intakes of alcohol, fibre, } \\
\text { carbohydrates and total energy }\end{array}$ \\
\hline Villegas et al. $(2007)^{(18)}$ & $\begin{array}{l}64227 \text { women aged } 40-70 \text { years, } \\
\text { China (1608) }\end{array}$ & $4 \cdot 6$ & FFQ & Confirmed self-report & GI and GL & $\begin{array}{l}\text { Age, WHR, smoking, physical activity, income, } \\
\text { education, occupation, hypertension, and } \\
\text { intakes of alcohol and total energy }\end{array}$ \\
\hline Sahyoun et al. $(2008)^{(19)}$ & $\begin{array}{l}3075 \text { adults aged } 70-79 \text { years, } \\
\text { USA (99) }\end{array}$ & 4 & $\mathrm{FFQ}$ & $\begin{array}{l}\text { Glucose levels, use of diabetic } \\
\text { medication and self-report }\end{array}$ & $\mathrm{Gl}$ and $\mathrm{GL}$ & $\begin{array}{l}\text { Age, BMI, sex, race, clinical site, education, physi- } \\
\text { cal activity, smoking, baseline fasting glucose, } \\
\text { and intakes of alcohol and cereal fibre }\end{array}$ \\
\hline Hopping et al. $(2010)^{(20)}$ & $\begin{array}{l}75512 \text { adults aged } 45-75 \text { years, } \\
\text { USA (8587) }\end{array}$ & 14 & FFQ & $\begin{array}{l}\text { Glucose levels, use of diabetic } \\
\text { medication and self-report }\end{array}$ & GL & $\begin{array}{l}\text { BMI, physical activity, education, race and total } \\
\text { energy intake }\end{array}$ \\
\hline Sluijs et al. $(2010)^{(21)}$ & $\begin{array}{l}37846 \text { adults aged } 21-70 \text { years, } \\
\text { The Netherlands }(915)\end{array}$ & 10 & $\mathrm{FFQ}$ & Confirmed self-report & GI and GL & $\begin{array}{l}\text { Age, BMI, waist circumference, sex, physical } \\
\text { activity, smoking, mean systolic blood pressure, } \\
\text { education, family history of diabetes, and } \\
\text { intakes of total energy, vitamin C, vitamin E, } \\
\text { protein, fat, alcohol and total fibre }\end{array}$ \\
\hline
\end{tabular}




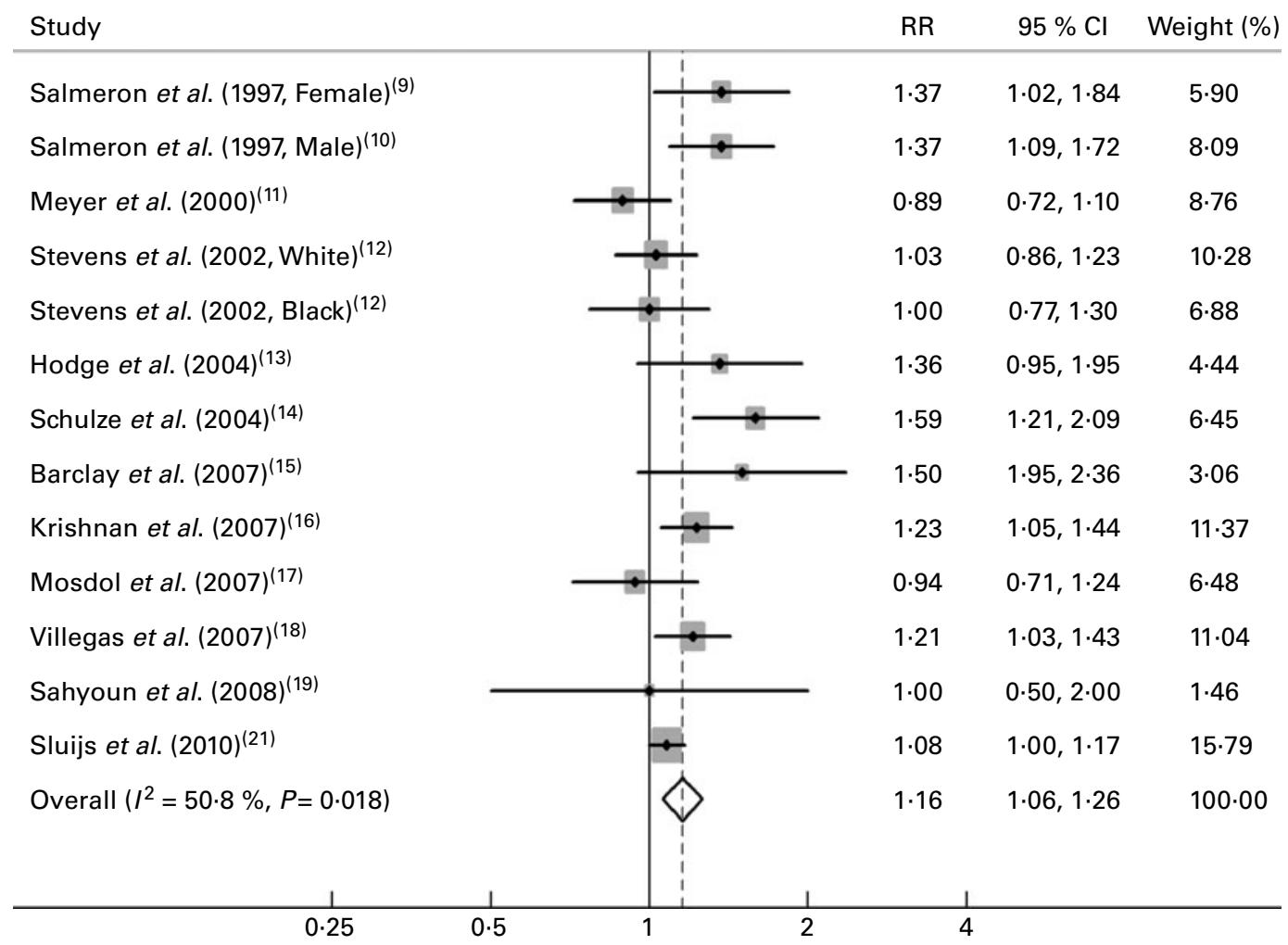

Fig. 1. Relative risks (RR) for the association between dietary glycaemic index and type 2 diabetes in prospective cohort studies.

RR of $1 \cdot 19(95 \%$ CI $1 \cdot 04,1 \cdot 36 ; n$ ) for the GI and $1 \cdot 22(95 \% \mathrm{CI}$ $1 \cdot 10,1 \cdot 36 ; n$ 9) for the GL. Further analyses investigating the influence of a single study on the overall risk estimate by omitting one study in each turn yielded a narrow range of RR from $1 \cdot 13(95 \%$ CI $1.04,1.22)$ to $1.18(95 \%$ CI $1.09,1.29)$ for the GI and from $1 \cdot 18(95 \%$ CI $1 \cdot 09,1 \cdot 28)$ to $1 \cdot 23$ (95\% CI $1 \cdot 15,1 \cdot 32)$ for the GL.

\section{Discussion}

The present meta-analysis of prospective cohort studies provides further evidence that higher dietary GI and GL increases the risk of type 2 diabetes. The highest GI and GL exposure compared with the lowest was associated with a 16 and $20 \%$ increase in diabetes risk, respectively. In addition, the associations persisted and remained statistically significant in the sensitivity analyses.

A major strength of the meta-analysis is that the present findings are based on prospective cohort studies. This minimises the possibility of recall and selection biases, which are always of concern in retrospective studies. Compared with the previous meta-analysis ${ }^{(22)}$, the risk estimates reported in the present study were a bit smaller. However, with accumulating evidence and enlarged sample size, we have enhanced statistical power to provide more precise and reliable risk estimates relating dietary GI and GL to diabetes risk.

Limitations of the present meta-analysis should also be acknowledged while interpreting the results. First, residual confounding is always of concern in observational studies. Although several important potential confounding factors, including age, BMI, physical activity and smoking, have been widely controlled in original studies, dietary factors were not sufficiently considered. For instance, higher GI was found to be correlated with lower intake of $\mathrm{Mg}^{(9,10,14)}$, and mounting evidence has suggested that lower $\mathrm{Mg}$ intake increases the risk of type 2 diabetes $^{(30)}$. Yet, few studies ${ }^{(14)}$ have adjusted for $\mathrm{Mg}$ in the multivariable analysis. In addition, it is possible that a low-GI diet is rich in plant foods containing many phytochemicals that may protect against diabetes, which could result in attenuated associations. Therefore, we could not exclude the likelihood that unmeasured or inaccurately measured factors may be responsible for the findings.

Second, misclassification error and bias may have weakened the strength of the associations. Misclassification of dietary assessment is not avoidable and misclassification of diabetes cases was likely to occur given that the majority of diabetes ascertainments were based on self-reports. In addition, most cohort studies measured dietary intakes at baseline only, and the lack of repeated dietary assessment during the follow-up period could also result in misclassification. Third, we observed heterogeneity among studies of GI and diabetes risk. This may be partly explained by variations in characteristics of study populations, measurements of dietary intakes and ranges of dietary GI exposure. We attempted to explore possible sources of variations in the results using sensitivity analyses, but significant heterogeneity remained unsatisfactorily explained. Nevertheless, differences in risk estimates among individual studies were mainly in the magnitude rather than the direction of the association. Fourth, because GL were highly correlated with carbohydrate intake, 


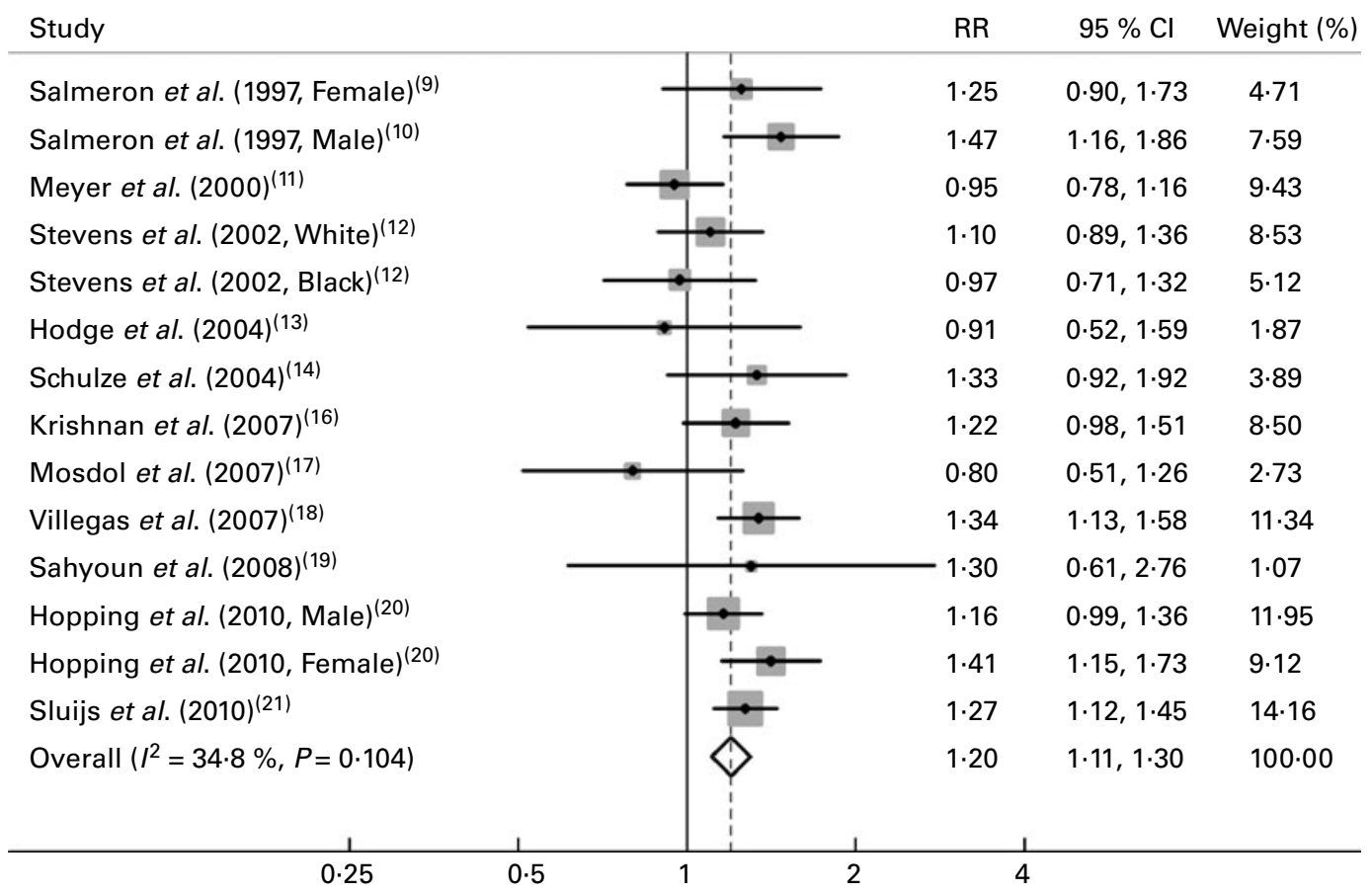

Fig. 2. Relative risks (RR) for the association between dietary glycaemic load and type 2 diabetes in prospective cohort studies.

it was difficult to determine to what extent the effect of GL on diabetes risk was explained by carbohydrate intake. Finally, publication bias could affect results of any meta-analyses. Yet formal statistical tests suggested little evidence of this bias in the present meta-analysis.

The exact mechanisms by which high-GI foods may increase the risk of type 2 diabetes are uncertain. A high-GI diet produces high concentrations of blood glucose and increased insulin demand. This could result in glucose intolerance and insulin resistance and eventually lead to a higher risk of type 2 diabetes $^{(8)}$. Furthermore, a high-GI diet could increase postprandial NEFA release, thereby directly increasing insulin resistance ${ }^{(7)}$. In addition, there is evidence that higher dietary GI is positively associated with subsequent gain in waist circumference ${ }^{(31)}$, which is a strong predictor of insulin resistance ${ }^{(32)}$ and diabetes risk ${ }^{(33)}$.

On the other hand, metabolic studies suggest that a low-GI diet may improve glycaemic control. A recent meta-analysis of seven randomised controlled trials conducted in diabetes has shown that a low-GI diet, compared with a control diet, significantly decreased glycated HbA1c, a long-term measure of blood glucose levels ${ }^{(34)}$. Although the reported decrease in glycated HbA1c was only $0.4 \%(95 \%$ CI $0.2,0.7)$ in that meta-analysis ${ }^{(34)}$, such a reduction has potential clinical importance as lowering glycated HbA1c by $0.6 \%$ was demonstrated to contribute to risk reductions of $32 \%$ for diabetesrelated clinical endpoints, $42 \%$ for diabetes-related deaths and $36 \%$ for all-cause mortality ${ }^{(35)}$.

The adverse effects of a high-GI diet may increase with an individual's underlying degree of insulin resistance ${ }^{(8)}$. Thus, several factors related to insulin resistance as well as diabetes risk, such as cereal fibre intake, physical activity and BMI, may have impacts on the associations between GI and GL and diabetes risk. Epidemiological studies have provided compelling evidence that lower cereal fibre intake is associated with an increased diabetes risk ${ }^{(30)}$. Previous studies ${ }^{(9,10,14)}$ have consistently suggested that the positive associations between GI and GL and diabetes risk were more pronounced among those with a lower intake of cereal fibre, with significant interaction. Physical activity has strong effects on glucose tolerance and insulin sensitivity ${ }^{(36)}$ and can significantly reduce the risk of developing type 2 diabetes ${ }^{(37)}$. As expected, the associations of GI and GL with diabetes risk appeared to be more evident in participants with low physical activity levels ${ }^{(14,18)}$. As for BMI, an important determinant of insulin resistance, results were inconsistent. For example, two studies $^{(14,18)}$ observed a stronger effect of GI and GL in participants with higher BMI, whereas another study ${ }^{(16)}$ showed a higher risk for GI and GL in those with lower BMI. Of note, the numbers of cases were relatively small in these stratified analyses, and therefore chance may, at least in part, account for these findings. Nevertheless, as potential effect modifiers, these variables need to be closely considered in subsequent studies for a better understanding of the relationships of dietary GI and GL to diabetes risk.

In conclusion, the present meta-analysis of prospective cohort studies provides further evidence in support of significantly positive associations between dietary GI and GL and the risk of type 2 diabetes. Given the wide exposure and the huge burden of diabetes worldwide, reducing the intake of high-GI foods, particularly refined carbohydrates, may bring potential benefits in diabetes prevention among the general population. 


\section{Acknowledgements}

This study was supported in part by the National Natural Science Foundation of China (no. 30771808). None of the authors had a conflict of interest. J.-Y. D. and L.-Q. Q. were responsible for the study design, data acquisition, statistical analysis and the interpretation of the results. J.-Y. D. prepared the manuscript. All authors critically reviewed the manuscript for important intellectual content and approved the final manuscript.

\section{References}

1. Wild S, Roglic G, Green A, et al. (2004) Global prevalence of diabetes: estimates for the year 2000 and projections for 2030. Diabetes Care 27, 1047-1053.

2. Sarwar N, Gao P, Seshasai SR, et al. (2010) Diabetes mellitus, fasting blood glucose concentration, and risk of vascular disease: a collaborative meta-analysis of 102 prospective studies. Lancet 375, 2215-2222.

3. Seshasai SR, Kaptoge S, Thompson A, et al. (2011) Diabetes mellitus, fasting glucose, and risk of cause-specific death. $N$ Engl J Med 364, 829-841.

4. Colditz GA, Manson JE, Stampfer MJ, et al. (1992) Diet and risk of clinical diabetes in women. Am J Clin Nutr $\mathbf{5 5}$ 1018-1023.

5. Knowler WC, Barrett-Connor E, Fowler SE, et al. (2002) Reduction in the incidence of type 2 diabetes with lifestyle intervention or metformin. $N$ Engl J Med 346, 393-403.

6. Jenkins DJ, Wolever TM, Taylor RH, et al. (1981) Glycemic index of foods: a physiological basis for carbohydrate exchange. Am J Clin Nutr 34, 362-366.

7. Ludwig DS (2002) The glycemic index: physiological mechanisms relating to obesity, diabetes, and cardiovascular disease. JAMA 287, 2414-2423.

8. Willett W, Manson J \& Liu S (2002) Glycemic index, glycemic load, and risk of type 2 diabetes. Am J Clin Nutr 76, 274S-280S.

9. Salmeron J, Ascherio A, Rimm EB, et al. (1997) Dietary fiber, glycemic load, and risk of NIDDM in men. Diabetes Care $\mathbf{2 0}$, 545-550.

10. Salmeron J, Manson JE, Stampfer MJ, et al. (1997) Dietary fiber, glycemic load, and risk of non-insulin-dependent diabetes mellitus in women. JAMA 277, 472-477.

11. Meyer KA, Kushi LH, Jacobs DR Jr, et al. (2000) Carbohydrates, dietary fiber, and incident type 2 diabetes in older women. Am J Clin Nutr 71, 921-930.

12. Stevens J, Ahn K, Juhaeri, et al. (2002) Dietary fiber intake and glycemic index and incidence of diabetes in AfricanAmerican and white adults: the ARIC study. Diabetes Care 25, 1715-1721.

13. Hodge AM, English DR, O'Dea K, et al. (2004) Glycemic index and dietary fiber and the risk of type 2 diabetes. Diabetes Care 27, 2701-2706.

14. Schulze MB, Liu S, Rimm EB, et al. (2004) Glycemic index, glycemic load, and dietary fiber intake and incidence of type 2 diabetes in younger and middle-aged women. Am J Clin Nutr 80, 348-356.

15. Barclay AW, Flood VM, Rochtchina E, et al. (2007) Glycemic index, dietary fiber, and risk of type 2 diabetes in a cohort of older Australians. Diabetes Care 30, 2811-2813.

16. Krishnan S, Rosenberg L, Singer M, et al. (2007) Glycemic index, glycemic load, and cereal fiber intake and risk of type 2 diabetes in US black women. Arch Intern Med 167, 2304-2309.

17. Mosdol A, Witte DR, Frost G, et al. (2007) Dietary glycemic index and glycemic load are associated with high-density-lipoprotein cholesterol at baseline but not with increased risk of diabetes in the Whitehall II study. Am J Clin Nutr 86, 988-994.

18. Villegas R, Liu S, Gao YT, et al. (2007) Prospective study of dietary carbohydrates, glycemic index, glycemic load, and incidence of type 2 diabetes mellitus in middle-aged Chinese women. Arch Intern Med 167, 2310-2316.

19. Sahyoun NR, Anderson AL, Tylavsky FA, et al. (2008) Dietary glycemic index and glycemic load and the risk of type 2 diabetes in older adults. Am J Clin Nutr 87, 126-131.

20. Hopping BN, Erber E, Grandinetti A, et al. (2010) Dietary fiber, magnesium, and glycemic load alter risk of type 2 diabetes in a multiethnic cohort in Hawaii. J Nutr 140, 68-74.

21. Sluijs I, van der Schouw YT, van der AD, et al. (2010) Carbohydrate quantity and quality and risk of type 2 diabetes in the European Prospective Investigation into Cancer and NutritionNetherlands (EPIC-NL) study. Am J Clin Nutr 92, 905-911.

22. Barclay AW, Petocz P, McMillan-Price J, et al. (2008) Glycemic index, glycemic load, and chronic disease risk - a meta-analysis of observational studies. Am J Clin Nutr 87, 627-637.

23. Higgins JP \& Thompson SG (2002) Quantifying heterogeneity in a meta-analysis. Stat Med 21, 1539-1558.

24. DerSimonian R \& Laird N (1986) Meta-analysis in clinical trials. Control Clin Trials 7, 177-188.

25. Begg CB \& Mazumdar M (1994) Operating characteristics of a rank correlation test for publication bias. Biometrics $\mathbf{5 0}$, 1088-1101.

26. Egger M, Davey Smith G, Schneider M, et al. (1997) Bias in meta-analysis detected by a simple, graphical test. BMJ 315, 629-634.

27. Zhang C, Liu S, Solomon CG, et al. (2006) Dietary fiber intake, dietary glycemic load, and the risk for gestational diabetes mellitus. Diabetes Care 29, 2223-2230.

28. Hu FB, Manson JE, Stampfer MJ, et al. (2001) Diet, lifestyle, and the risk of type 2 diabetes mellitus in women. $N$ Engl J Med 345, 790-797.

29. Halton TL, Liu S, Manson JE, et al. (2008) Low-carbohydratediet score and risk of type 2 diabetes in women. Am J Clin Nutr 87, 339-346.

30. Schulze MB, Schulz M, Heidemann C, et al. (2007) Fiber and magnesium intake and incidence of type 2 diabetes: a prospective study and meta-analysis. Arch Intern Med 167, 956-965.

31. Du H, van der AD, van Bakel MM, et al. (2009) Dietary glycaemic index, glycaemic load and subsequent changes of weight and waist circumference in European men and women. Int J Obes (Lond) 33, 1280-1288.

32. Racette SB, Evans EM, Weiss EP, et al. (2006) Abdominal adiposity is a stronger predictor of insulin resistance than fitness among 50-95 year olds. Diabetes Care 29, 673-678.

33. Vazquez G, Duval S, Jacobs DR Jr, et al. (2007) Comparison of body mass index, waist circumference, and waist/hip ratio in predicting incident diabetes: a meta-analysis. Epidemiol Rev 29, 115-128.

34. Thomas DE \& Elliott EJ (2010) The use of low-glycaemic index diets in diabetes control. Br J Nutr 104, 797-802.

35. UK Prospective Diabetes Study (UKPDS) Group (1998) Effect of intensive blood-glucose control with metformin on complications in overweight patients with type 2 diabetes (UKPDS 34). Lancet 352, 854-865.

36. Goodyear LJ \& Kahn BB (1998) Exercise, glucose transport, and insulin sensitivity. Annu Rev Med 49, 235-261.

37. Jeon CY, Lokken RP, Hu FB, et al. (2007) Physical activity of moderate intensity and risk of type 2 diabetes: a systematic review. Diabetes Care 30, 744-752. 